\title{
Feels Like Home: Home Staging, Materiality and Embodied Consumption
}

Kelcie L. Vercel

University of Notre Dame

\begin{abstract}
:
Bringing together research on culture, materiality and consumption, I conceptualize home stagers as market and cultural intermediaries who do their work in the space between a home (the product) and potential homebuyers (the consumer). Using data from the content analysis of nearly 200 staging documents, as well as from interviews and observations with home stagers, I describe the strategic cultural and material work performed by home stagers as they attempt to construct the optimal purchasing experience for potential buyers. Specifically, I examine how home stagers convey a home's livability to buyers by using material objects to influence their senses, imaginations and processes of evaluation. In so doing, I reveal a previously overlooked process that shapes the most consequential consumption decision most people will ever make (Koklic and Vida 2009), and describe how this process may act as a mechanism of exclusion. I also contribute to work on cultural intermediaries more generally by describing two new dimensions along which their practices may vary: neutrality and temporal orientation.
\end{abstract}

Keywords: Cultural sociology; Meaning; Experience economy; Housing; Cultural mediation

\section{Introduction}

This project is motivated by the broad question: How is the experience of shopping for a home culturally constructed for potential homebuyers? Existing data on home ownership in America reveals who is most likely to purchase a home and what discrete factors are important in buyers' decision making (e.g. price and location, Anderson 2017). However, even given the wealth of research on the cultural significance of home ownership in the US context, the cultural meanings and processes that undergird the experience of buying a home remain implicit.

Research on home buying reveals that potential buyers prefer to purchase a house that aligns with their sense of self or in which they experience a sense of belonging (Koklic and Vida 2009;

Sirgy, Grzeskowiak, and Su 2005); buyers may be motivated by the longing for a particular 
lifestyle (Jørgensen 2015; Munro and Smith 2008) or by anxiety about possible negative housing situations or experiences (Christie, Smith, and Munro 2008; Low 2008; Low 2001). However, and importantly, potential homebuyers' perceptions of belonging, desirability and security in a particular house are not inevitable; rather their experiences are deliberately shaped by market intermediaries like realtors (Besbris 2016) and home stagers, both through social interaction and by the way these actors - along with home sellers-configure the physical space of the house.

Scholars have largely overlooked how these actors strategically manage the material qualities of houses in order to influence buyers' perceptions of their value and desirability (though Avitts 2014 is a notable exception). Bringing together research on culture, materiality and consumption, I conceptualize home stagers as market and cultural intermediaries who do their work in the space between a home (the product) and potential homebuyers (the consumer). ${ }^{1}$ Using data from the content analysis of nearly 200 staging documents, as well as from interviews and observations with home stagers, I describe the cultural and material work performed by home stagers as they attempt to construct an embodied consumption experience that will lead potential homebuyers to make an offer. In so doing, I reveal a previously overlooked process that shapes the largest and most consequential consumption decision most people will ever make (Koklic and Vida 2009).

I also contribute to work on culture and materiality by detailing the strategies of cultural intermediaries outside the fields of the arts and entertainment, who face the difficulty of

\footnotetext{
${ }^{1}$ I use the term 'cultural intermediaries' to capture the distinct role of these workers, with whom I class home stagers. Cultural intermediaries (also called the "new petite bourgeoisie" by Bourdieu [1984:359]) are those working in "all the occupations involving presentation and representation (sales, marketing, advertising, public relations, fashion, decoration and so forth) and in all the institutions providing symbolic goods and services. These include the various jobs in medical and social assistance... and in cultural production and organization..." (ibid). They work between the production and consumption of an object (Cronin 2004). While Bourdieu's definition of the category is quite broad (Negus 2002), I am looking at home stagers as members of a particular subset of cultural intermediaries: those who orchestrate experiences for consumers. Home stagers, curators, customer experience managers and others work on the material environment of consumption in order to communicate desired symbolic meanings and facilitate desired embodied experiences.
} 
constructing an experience for consumers that will reliably lead to a specific desired action. By attending to the material practices that home stagers develop to mediate between the house as a cultural object and the potential buyer as a consumer, I provide new insight into the work cultural intermediaries do, and offer additional ways of understanding how the connection between cultural object and consumer is forged. Specifically, I describe how stagers' strategies vary along two continua: neutrality and temporal orientation. Stagers' practices range from those that target a generic or universal buyer to those that target a very specific or even a singular buyer. Their strategies also span a range of temporal orientations, as they attempt to control buyers' perceptions of the home's past and its previous owners, to convey optimal desirability in the present, and to encourage the buyer to imagine their future life in the house.

\section{Embodied Experience in Consumption Settings}

My goal in this analysis is to bring together research detailing the role of experience and emotion in economic decisions, with the insights of sociologists studying culture and materiality. Bringing these two bodies of knowledge together allows me to think more precisely about the cultural work performed by home stagers as they attempt to imbue the buying experience of potential homebuyers with particular emotional and cultural associations.

Cultural producers and intermediaries across diverse industries are invested in crafting a particular kind of experience for their consumers in the hopes that they will solidify consumers' brand loyalty or meet other organizational goals, and there is a wealth of scholarship that discusses how best to engage, please and retain one's customers (e.g. Ellis and Rossman 2008; Holbrook and Hirschman 1982; Knutson and Beck 2004; Tsai 2005). Providing one's customers or clients with a compelling and exemplary experience is considered essential to success in the current economy (Tsai 2005). This is even more true with the growth of what many call the 
"Experience Economy," which has focused attention on how companies can construct memorable and effective experiences for their customers (Pine and Gilmore 1999; Ellis and Rossman 2008; Hayes and MacLeod 2016; Knutson and Beck 2004). These efforts are rooted in the acknowledgment that consumers' purchase decisions are influenced by their mood (Swinyard 1993), emotions (Bandelj 2009; Holbrook and Hirschman 1982), intuition (Mitchell and Beach 1990) and interactions (Bettman, Luce, and Payne 1998). By crafting an attractive, engaging and memorable physical environment for consumers, companies can increase consumers' perceptions of product quality (Iyer and Kuksov 2010), and increase the likelihood that consumers will return (Ellis and Rossman 2008).

As this attention to consumers' emotions and experiences implies, consumption decisions are importantly embodied (Warde 2014). Consumers do not evaluate and purchase products in a vacuum of objectivity or abstraction; rather, their decisions are influenced by a range of factors, both internal and external (Koklic and Vida 2009). In addition to the impact of consumers' current mood, the sensory stimuli of the environment, and their interaction with others in the environment, consumers' own history and set of experiences exert influence on their consumption decisions. Their embodied sociocultural history shapes their taste and the cultural objects with which they feel an affinity (Bourdieu 1984). This affinity has been variously described as an embodied sense of "fit" (Allen 2002), as "resonance" (Schudson 1989), and as "self-congruity" (Sirgy et al. 2005). This match between person and product is important for consumption decisions in general, and should be even more so for houses, which are charged with cultural meanings regarding inhabitants' social networks and status in the broader social world (Douglas 1991; Hurdley 2006), with inhabitants' remembered past and imagined future (Csikszenthmihalyi and Rochberg-Halton 1981; Marx, Solomon, and Miller 2004; Rogers 2013), 
and with assumptions about the ideal family and the ideal home (Chapman and Hockey 2002; Dickinson, Malone Maugh, and Kaston Tange 2004; Gillis 1997; Golab 2013). In order to understand home buying in the United States, it is necessary to investigate how the material context of home buying is constructed for homebuyers.

\section{Connecting Culture, Materiality and Experience in Selling a Home}

Sociologists have recently brought attention to the role of the material environment in shaping how people experience and interpret cultural objects (Babon 2006; Grazian 2012; Griswold, Mangione, and McDonnell 2013; McDonnell 2010). An encounter with a cultural object does not lead to one, predictable interpretation on the part of the audience or consumer (McDonnell 2010). Instead, tangible qualities of the object interact with schemas, knowledge and habits brought into the encounter by the consumer, and meaning emerges from that interaction (Griswold 1987). While cultural intermediaries cannot control all of what is brought into that encounter by the consumer, they may arrange the material environment to encourage the interpretation or experience they desire. The material qualities of environments are open to the manipulation of cultural intermediaries as they attempt to shape their audience's experience and response (Bartram 2017).

As cultural intermediaries work to influence their clients or consumers, their efforts are grounded in and constrained by the conventions of the type of space in which they are working (Grazian 2012; Griswold et al. 2013). Conventions help people anticipate and interpret what kinds of things they will experience or be expected to do in a particular context. In a museum, convention holds that all the objects on display have been recognized as bona fide art, conversation should be hushed, and art should be looked at - but not touched. Conventions help visitors make sense of the space, so curators and artists may play off those conventions to help 
convey the meanings and experiences they desire to evoke (Griswold et al. 2013). This principle holds for other cultural intermediaries attempting to construct experiences for visitors or clients; whether curating museums (Bartram 2017; Griswold 1981; Jansen 2008; Turner 2012), designing zoos (Grazian 2012), planning amusement parks (Ellis and Rossman 2008), constructing tourist attractions (Cohen 1988; Hayes and MacLeod 2016), or managing shopping experiences (Iyer and Kuksov 2010; Tsai 2005), cultural intermediaries across industries use the material environment to construct experiences for their clients.

As I tracked stagers' practices, and observed how they talk about their goals and their triumphs, it became clear to me that they are engaged in precisely this type of cultural and material work. They strive to convey desirable meanings and images of home through material objects in order to forge a connection between the house and the buyer. Grounded in the conventions of the American home, stagers attempt to inspire these feelings in buyers through their embodied experience within the material environment of the house. They rearrange and decorate rooms to conform to people's expectations for what types of rooms a home should have (i.e. that catchall room with the computer desk, treadmill and crib gets turned back into a standard bedroom or a home office). They draw on conventional meanings of home-like the home as a refuge or safe haven (Bright and Hopkins 2011; Graham, Gosling, and Travis 2015; Konieczny 2009; Mallett 2004) - when they are constructing buyers' experiences, as when they paint bathroom walls blue in the hopes that buyers will experience it as soothing and restful. Stagers, as cultural intermediaries, draw upon material and visual rhetorics to shape consumers' experiences in a space (Bartram 2017; Dickinson et al. 2004). These rhetorics are persuasive and meaning-laden narratives expressed through material objects and spaces (Bartram 2017), and they embed consumers within their narrative by appealing to their senses (Dickinson et al. 2004). 
Stagers engage all of visitors' senses to give them an experience that evokes positive emotions and encourages buyers to ascribe positive meanings to the house.

From the buyer's side, a range of cultural and economic research has indicated the influence of embodied experience and emotion in the home buying decision. Buyers often describe an intangible feeling of 'rightness' or of feeling 'at home' in the house they ultimately buy (Christie et al. 2008; Jørgensen 2015; Munro and Smith 2008). Finding the right home is often associated with emotions of love and belonging (Christie et al. 2008; Garber 2000; Munro and Smith 2008). Scholars have noted the significance of identity and lifestyle matching in buyers' decision-making (Gram Hanssen and Bech Danielsen 2004; Koklic and Vida 2009; Sirgy et al.2005), and there are some excellent analyses of the role of emotion in home buying and selling (see Besbris 2016; Christie et al. 2008; Munro and Smith 2008). Emotions play an important role in the home buying decision (Jørgensen 2015; Koklic and Vida 2009; Munro and Smith 2008), and buyers' emotions may be influenced by market intermediaries in several ways. Home builders may attempt to encourage feelings of desire and belonging by alluding to aspirational lifestyles through a house's layout and décor (Golab 2013). Builders may also work to increase a buyers' confidence in their product through their sales and marketing strategies (Koklic and Vida 2009). Real estate agents may cultivate feelings of urgency, confidence and belonging that encourage buyers to make a purchase decision (Besbris 2016). Home stagers arrange the contents of houses to suggest an aspirational lifestyle that maps onto the cultural ideal of family life and encourages buyers to imagine themselves living that ideal life (Avitts 2014).

The importance of the relationship between experience, emotion and the material qualities of a house is indicated by these studies, and by research on the home buying industry 
from outside academia. Almost $80 \%$ of homebuyers in the US report that going on a home tour was vital to their decision (Anderson et al. 2017). This finding suggests that buyers seek an embodied experience in the material environment of a house, over and above objective factors like price and location, which can be determined online or in an advertisement. Buying a home is the most significant singular purchase most people make (Besbris 2016; Bourdieu 2005; Koklic and Vida 2009), and buyers' emotional and aspirational connections to a house weigh alongside their financial investment (Christie et al. 2008; Jørgensen 2015; Munro and Smith 2008). Given both the literature examining other types of cultural intermediaries and their influence on consumers through the careful arrangement of material environments, and this evidence regarding the emotional and experiential aspects of home buying, it seems clear that home buying cannot be understood without an explanation of how homes are staged for potential buyers. Existing research suggests that the cultural and material work of intermediaries may influence homebuyers (Besbris 2016; Bourdieu 2005; Munro and Smith 2008), but there is almost no research on the strategic ways that houses are arranged to provide potential buyers with specific embodied experiences (though Avitts 2014) offers a description of the symbolic dimension of staging). I argue that stagers attempt to encourage buyers to purchase houses by targeting buyers' senses, emotions, imagination, and reason, and that their strategies are grounded in an implicit vision of livability and how to communicate livability to buyers.

It is important to note that even though this analysis centers on the practices of professional home stagers, I intend the argument put forth here to apply to those who do this work informally. Many sellers do not employ a professional home stager. However, both owner/sellers and realtors are highly involved in preparing a home for sale, and this usually entails some degree of arranging and altering the material qualities and physical appearance of a 
home. Sellers and realtors are both privy to the many conventions of home, and to ideas about what buyers expect to experience when they tour a home. Whether or not they engage in an explicit discourse - as stagers do-about these expectations and how to meet them, they are still likely to put effort into arranging the material qualities of the house in order to encourage a sale. And even if a buyer changes absolutely nothing - and even leaves their smelly dishes in the sink during a home tour-my findings offer an improved lens for examining why these sensory cues are significant in the home buying process (even though dirty dishes have no objective relationship to the value of a house).

\section{Livability}

Based on the findings of my analysis, I introduce the concept of 'livability' ${ }^{2}$ to describe the multifaceted quality that stagers seek to communicate to buyers through the material properties of a home for sale. Livability, or the degree to which a house is perceived to be desirable, valuable and compatible with a buyer's current and anticipated lifestyle, is established through sensory and cognitive cues. Or, at least, home stagers believe this is true, and so they concentrate their efforts on disciplining the material environment of the house so that it will give off the right combination of these cues. They want buyers to experience a home's livability when they tour it with a realtor; they want buyers to perceive a home as eminently livable.

The concept of livability is effective for thinking about the embodied experience that stagers strive to construct for buyers for several reasons. Livability conveys the embodied dimensions and temporal orientation of home buying. In contrast to concepts like "congruity" (Sirgy et al. 2005) and salability, livability indicates the embodied and experiential dimension of

\footnotetext{
${ }^{2}$ The term 'livability' is used in real estate research as an indicator of a buyer's desire to live in a particular house (e.g. Lane, M. J. Seiler, and V. L. Seiler 2015). While the concept of livability I develop here includes desirability, it also includes perceptions of belonging or congruence, and of relative value. Additionally, I emphasize livability not as a discrete reported degree of desire, but as an embodied experience buyers have within the material environment of a house.
} 
finding the right home. Livability captures not just a static match between buyer and house, but the reality that the home is a practice (Gram Hanssen and Bech Danielsen 2004; Halton 2008; Konieczny 2009), and that a desirable home is one that can facilitate a person's lifestyle now and in the future: a house in which one can imagine comfortably doing the business of living. Livability is not narrowly rational, nor is it exclusively emotional or psychological. It encompasses a dynamic interaction of the practical, cultural and emotional concerns that guide homebuyers' decisions. Using the concept of livability, I can acknowledge that homebuyers' lifestyles and self-concepts influence their sense of what is practical (Koklic and Vida 2009). Finally, livability - as I have observed and conceptualized it - may be constructed and influenced by market and cultural intermediaries, and therefore is susceptible to social dynamics like stereotyping and implicit bias. Analyzing how stagers attempt to construct experiences of livability for homebuyers can offer insight into more hidden aspects of the accessibility of housing.

\section{Data and Methods}

\section{Data}

The primary data for this analysis consists of 194 documents relating to the practice of home staging. To build this sample, I collected every article listed in the categories of "Staging" and "Staging Tips" from Staged, Styled \& Sold, a section of REALTOR® Mag, the online magazine of the National Association of Realtors (NAR). This resulted in a dataset of 163 documents. After developing a coding scheme based on these documents and identifying important themes, I selected additional articles related to those themes from industry sources to complete the analysis. These sources included other sections of REALTOR ${ }^{\circledR}$ Mag, and other sources of home stager credentialing and professionalization, like Home Staging Resource and Certified Staging Professionals ${ }^{\circledR}$. The articles date from 2009 to 2017. A full list of these 
documents is included in Appendix 1. Quotes from these documents are cited using the format "DX", where X corresponds to the number assigned to that document in the appendix.

Staged, Styled \& Sold is an optimal source for accessing official industry discourse about stagers and the staging industry. Because there is no single, centralized credentialing body for home stagers, NAR provides an established industry perspective on staging. By dint of its status in the real estate field, this forum also serves as a type of clearinghouse, where a variety of prominent actors from the staging industry are given a platform. This variety yields a fuller view of the staging industry than could be obtained with data from a single staging credentialing organization (e.g. International Association of Home Staging Professionals or the Real Estate Staging Association). Additionally, the blog format of the magazine permits comments from readers, which allowed me to observe instances of both consensus and disagreement among industry actors.

When relevant, I also draw upon data from 20 interviews and 13 home tours of for-sale houses with varying degrees of staging. Interviews were conducted between 2015-2017 with homebuyers and housing professionals in a variety of settings, including during open houses, in newly purchased homes, and over Skype. Interviews were audio recorded, transcribed and then analyzed using the established coding scheme. I documented all home tours and observations in detailed field notes, and in eight of the thirteen homes, I supplemented my field notes with photographs.

\section{Method of Analysis}

I began the content analysis with an interest in understanding how stagers attempt to shape homebuyers' decisions and experiences. I wanted to understand how stagers think about their work and what kinds of cultural ideas about home are implicit in their practices. I began 
open coding with the first (chronologically) 100 documents. In the process of open coding, all content must be assigned a code, and new codes are added as new themes and phenomena are encountered (Johnson and Holmes 2009; Strauss and Corbin 2007). During this open coding process, I created 46 codes to describe all of the material in the articles. After analyzing my fieldwork for similar themes, I added eight new codes to my coding scheme. As I analyzed the themes that emerged in the initial coding, I identified connections between codes - as might be described by axial codes (Strauss and Corbin 1990) - and I created four new codes to capture these analytical insights. Before I revisited the data to recode with this set of codes, I examined my codes for clarity, specificity, and consistency. I considered which codes might be redundant or conflate multiple themes. I combined some codes and separated out others into multiple codes. I then recoded all of the documents using this coding scheme. After completing this process, I determined that some of the codes were not relevant to the current analysis. Below are the 54 codes I used in my final analysis, broken down into analytical categories and listed with the number of quotations to which each code was applied (Figure 1).

These procedures were carried out using the qualitative data analysis software Atlas.ti. I imported all of the documents into this program, and then was able to create and assign codes to content, examine the data by code, code group, document and quotation, and to track code occurrence and co-occurrence rates. I also generated memos on themes and concepts as they emerged-like embodiment, envisioning and the professional status of staging - to guide my analysis and flesh out connections between codes and concepts. As suggested by this description, I used a combination of inductive (Glaser and Strauss 1967) and abductive (Timmermans and Tavory 2012) strategies to generate and assign codes to all of the content, and then to analyze the connections between the codes. I began with two broad questions: 1) How do home stagers 
attempt to influence homebuyers? and 2) How do home stagers talk about the work they do? These questions oriented me to identifying home stagers' strategies and the discourses they develop to describe and justify these strategies.

Figure 1. 

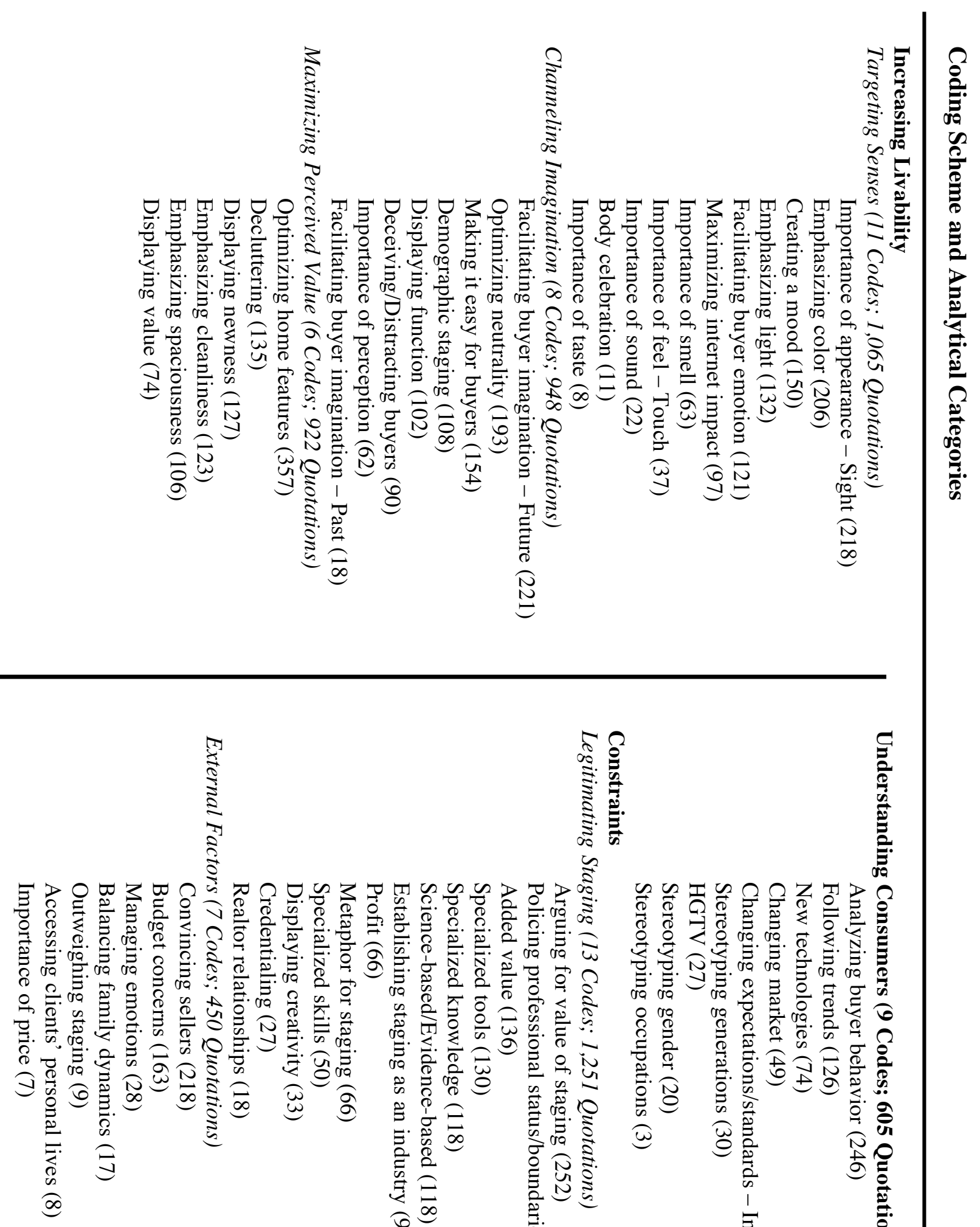


\section{Findings \& Discussion}

\section{Cultural Work in a Quasi-Legitimized Industry}

In order to understand the discourse I observed in staging documents and the strategies that home stagers develop, it is essential to understand the field position of the staging industry. Staging (referred to as both 'home staging' and 'real estate staging') is the process of preparing a home for sale to make it appealing to buyers, and may encompass activities ranging from cleaning and de-cluttering to renovation. ${ }^{3}$ While home staging has become more widely recognized as its own industry, distinct from the related fields of real estate and interior decorating, it has neither absolute acceptance nor clear industry boundaries. Mary Umberger captures this ambivalence in her article in the Los Angeles Times: "[Staging is] a specialty within the world of real estate that has passionate proponents who say it creates an idealized view of "home" that makes someone want to buy it. Skeptics say it can be expensive and time-consuming and doesn't necessarily make any difference in getting a place sold" (Umberger 2011). In a 2017 report from the National Association of REALTORS ${ }^{\circ}$, only $38 \%$ of sellers' agents reported staging all homes before putting them on the market, though $77 \%$ of buyers' agents thought staging helped buyers visualize a house as their future home (Dunn 2017). In the same report, more than $60 \%$ of agents thought staging decreased the amount of time houses spent on the market, but $24 \%$ thought it had no impact or even increased time on the market (the remaining agents responded 'Don't know') (Dunn 2017). At the same time, staging organizations claim that staged homes spend $88 \%$ less time on the market (Shwarz n.d.). This lack of consensus about the effectiveness of home staging is also reflected in how often I applied the code Convincing sellers

\footnotetext{
${ }^{3}$ Barb Schwarz, a real estate broker and the creator of the Accredited Staging Professional® and International Association of Home Staging Professionals ${ }^{\circledR}$ credentialing program, is credited with first naming and describing home staging as a distinct practice and industry in 1972 (stagedhomes.com).
} 
(218 occurrences) in my content analysis, as stagers offered tips and anecdotes about how best to convince sellers that staging is worth the investment of time and money.

There is also ambiguity in who counts as a stager and what, precisely, a stager does. If a realtor advises his or her clients to de-clutter and rearrange their furniture before listing their house for sale, is this staging? If the sellers decide to repaint their house with neutral colors and take down their personal photos, does this count as staging? Or should these be called partial staging? Or amateur staging? There is also organizational overlap between the real estate industry and the home staging industry, as realtors may earn a certification in home staging to advance their professional profile, or they may perform aspects of staging informally. Individuals outside the real estate industry may also receive training through any of the multiple independent credentialing agencies (e.g. Certified Staging Professionals ${ }^{\circledR}$, Real Estate Staging Association ${ }^{\circledR}$, Accredited Staging Professionals ${ }^{\circledR}$, and International Association of Home Staging Professionals $\left.{ }^{\circledR}\right)$, and these stagers might have experience in interior design or marketing, rather than in real estate. These field dynamics shape how stagers talk about and pursue their work. Because of the ambiguity around their work and professional status, stagers lack clear practical guidelines or benchmarks. As a result, they are more likely to fall back on implicit schemas, cultural assumptions, and idiosyncratic preferences to guide their choices (Bielby and Bielby 1994). This has important implications for the cultural meanings they communicate through the material features of houses.

While the discursive work performed by home stagers around legitimizing home staging might reasonably merit an in-depth analysis of its own, my analysis suggests that this ambiguity is best understood as the context for stagers' primary cultural project: the construction of livability. Their attempts to convey houses as livable are constrained by their tenuous field 
position, and their discourse and strategies often revolve around trying to mitigate the ambiguity of their work. In order to increase clarity about what they do and why it is valuable, they align staging with other fields and industries that are perceived as legitimate, as when they assert that their practices are supported by evidence, science or statistics (code: Science-based/Evidencebased). They also appeal to expertise when they emphasize their specialized training and resources (codes: Credentialing; Specialized tools; Specialized knowledge; Specialized skills). They seek to clarify what buyers want and what compels them to make a purchase by analyzing buyer behavior (codes: Analyzing buyer behavior; Stereotyping generations; Stereotyping gender; Stereotyping occupations). And they increase clarity about which staging practices align with buyers' preferences and needs most closely by sharing success stories (code: Added value) and engaging in spirited debate around best practices and outmoded techniques (codes: Following trends; Changing market; Policing professional status/boundaries).

\section{Optimizing Buyers’ Experience/Constructing Livability}

Livability, as stagers' cultural and material project, is based on what stagers believe about homebuyers and what motivates them to purchase a home. From stagers' strategies and accounts, I discern three primary aspects of livability, as they imagine it is perceived and experienced by buyers. They believe that in order to buy a house, buyers: 1) Must be able to envision themselves living in a house, 2) Must be attracted to the house or desire to live in it, and 3) Must regard the house as a good value for the price. These three beliefs about what is required for a buyer to make a purchase ground stagers' practices. Figure 1. displays the many practices stagers employ in their efforts to increase a house's perceived livability (code category: Increasing Livability). I have divided these practices into three broad subcategories: Targeting Senses, Channeling Imagination, and Maximizing Perceived Value. These categories describe the different kinds of 
strategies stagers have developed in their efforts to achieve the three goals above. Stagers

attempt to influence buyers senses, imaginations and processes of evaluation in order to facilitate an experience of livability.

\section{Targeting Senses}

Shopping for a house is an embodied process, and stagers attempt to convey livability to potential buyers through their senses (code category: Targeting Senses), including through visual cues (code: Importance of appearance - Sight). Stagers draw upon psychological and folk accounts of the relationship between sensory experiences and emotions in their attempts to create sensory atmospheres conducive to purchasing decisions. In their efforts to establish effective material strategies for conveying livability, stagers often link their practices with evidence- or science-based principles (code: Science-based/Evidence-based). For example, "color theory" was invoked to guide stagers' choices of paint colors for their clients' homes.

Blue is known as a soothing color that can be mentally calming. Blue actually tends to surface universally as the world's favorite color, according to research, so you're probably not going to turn off too many buyers by incorporating blue. However, you also don't want to give people the "blues." Sometimes blue has been found to be perceived as cold or unfriendly, so don't overdo it.

Try it: A soft blue color in the bathroom or bedroom may just be the calming retreat you want to create in a home you have for sale. (D54)

Here, the writer suggests that blue walls might make a potential buyer feel calm and soothed in a house, and so might increase the buyer's attraction to the home. The author is attempting to translate a psychological finding into a material practice in order to evoke emotions in potential homebuyers that will make them more likely to make a purchase. At the same time, the author warns against using too much blue, as this might be experienced as 'cold' by homebuyers. These references to psychology are combined with conventional understandings of the role of the home as a "retreat" to formulate a tangible material practice. In this case, a visual cue (the color blue) 
is expected to evoke suitable emotions and connotations for conveying livability. In the face of the uncertainty that characterizes their work, home stagers reach for many different cultural resources to guide their choices.

Others draw upon a similar framework - though in folk terms - to argue for color's powerful potential impact on buyers. One realtor commented on an article about neutralizing the seller's home, saying: "I disagree with "de-personalizing" a home....Bold wall colors also make people fall instantly in love. It attracts the same kind of person that lives there and "bam" the house is sold." (D89) This writer implies that bold colors evoke strong positive emotions, and these emotions generate a personal connection with the physical space (code: Emphasizing color). The association between feelings of love and selecting a house is borne out by research (Garber 2000; Munro and Smith 2008), and this writer believes that bold colors are a visual catalyst for feelings of love. This comment succinctly describes the "fits-like-a-glove" (Allen 2002) moment that stagers want buyers to experience, and argues that wall color can facilitate that experience. Also of note in this statement is the implicit recognition that the efficacy of color in provoking this response is based on an alignment between the lifestyle reflected by the color and the lifestyle of the potential buyer. The author here is in conversation with a common theme in the staging documents: the importance of depersonalizing and neutralizing a home for sale (code: Optimizing neutrality). Stagers often recommend neutralizing one's décor and removing personal items so that it will be easier for buyers to imagine themselves into the space (codes: Decluttering; Facilitating buyer imagination). At the same time, stagers often try to arrange the material conditions of a home to appeal to an imagined buyer, whether as a broad demographic (e.g. a middle-class family) or a very specific buyer (e.g. an urban professional couple in their 30 's who work in the tech industry). In the above comment, the author argues that retaining the 
current owner's bold colors might make the home appeal to someone with similar tastes and lifestyle, leading to a faster-"bam"- sale than if the house was neutralized to appeal to a generic buyer. This comment's posture of disagreement reveals the tension between these two poles, the generic and the specific, in stagers' material strategies.

Visual cues are not the only way that stagers attempt to provide a powerful sensory experience for potential buyers. They also emphasize the importance of how a house smells to potential buyers, and express many and contradicting ideas about how to optimize buyers' olfactory experiences (code: Importance of smell). Stagers use specific aromas to evoke moods and feelings that they expect to increase buyers' perceptions of the home's livability. These aromas were often touted as creating a "warm," "inviting," or "cozy" atmosphere in the house, rather than being connected to concrete reasons a buyer might choose to buy or not buy. For example, one article offered the following advice for staging houses in the winter:

Offer up some cozy smells: "We take some big old pots and dump cider in them, then warm it up and the whole house smells good," Idaho real estate professional Gail Hartnett told AOL Real Estate. "It's just a warm, homey smell that makes people feel good when they enter." (D98)

Here, a "homey" smell is expected to contribute to a house's perceived livability by making people feel at home in the house (code: Facilitating buyer emotion; Creating a mood). There may be no demonstrable connection between the smell of hot cider and the value of a house, but stagers believe that a buyer's overall sensory experience in a house influences that house's perceived livability, and that strategically selected scents can improve this sensory experience. Many agree that the most important smell is one of "cleanliness" (code: Emphasizing cleanliness): “The best scent is no scent! Clean, clean, clean!” (D94) Stagers and realtors highlight perceptions of cleanliness, conveyed through both sights and aromas, as essential to livability. Cleanliness is generally considered to be universally appealing, but this assumption of 
universality is shaped by stagers' cultural context. Cultural classification systems dictate norms of hygiene, and these norms give meaning to objects and their location (Douglas 2003). In the United States, the home is closely associated with the self and with personal autonomy: traces of previous owners in one's home are unsettling and objectionable (Hockey 2002). Signs of the current owner of a house, especially sights and smells that might be perceived as unclean, violate our cultural meanings of home (Kaika 2004) and are thus an obstacle to buyers' perceptions of livability. For this reason, stagers try to minimize any material signs of the current owners. As realtor and stager Karen Winters told me, "You want it to look like someone could live in this house, not like someone is living in this house" (Staging observation, 6/11/17). Karen's also comments reveal the temporal dimension of stagers' material strategies. She wants buyers to imagine what their lives could be like in a house (code: Facilitating buyer imagination - Future), while preventing them from thinking too much about the people who have been living in the house (code: Facilitating buyer imagination - Past).

Scents were also used in connection with tactile and visual elements in order to encourage desirable connotations (codes: Importance offeel-Touch; Importance of appearance - Sight; Creating a mood). One stager suggests, “To create a spa-like ambience that evokes relaxation and tranquility, try folding and layering bright white or colorful fluffy towels on countertops and towel bars. Lightly scented candles, soaps, and lotions with attractive packaging will provide a feeling of self-indulgence.”(D147) Here, the stager constructs a visual, tactile and olfactory scene that she hopes will trigger positive associations with spas and leisure, resulting in feelings of "relaxation," "tranquility," and "self-indulgence," and ultimately increasing the home's appeal (code: Body celebration). These sensory goals are built upon cultural meanings of the home, including the home as a haven (Bright and Hopkins 2011; Graham et al. 2015; 
Konieczny 2009; Mallett 2004), and the growing expectation that the bathroom should serve as a realm for "body celebration" (Chapman 2002).

Stagers were also encouraged to use sounds to create certain "moods" for homebuyers (codes: Importance of sound; Creating a mood).

Make sure all lights and lamps are on for showings, and set an inviting mood: Have soft background music turned on (such as light FM music). (D171)

Create ambiance and character in the home with well-thought out placement of sensory and lifestyle components. Soft music, lighting on dimmers, candles lit, and fresh floral are all great ideas for broker or open houses. (D88)

All of these efforts are aimed at constructing a sensory experience of livability for potential buyers as they walk through a house. Stagers believe they can use the material environmentpaint colors, stacks of towels, hot cider bubbling on the stove - to trigger positive emotions in buyers that will forge a connection between them and the house, and ultimately increase the likelihood that buyers will make a purchase. Stagers draw upon both scientific and folk knowledge to justify and guide their practices, and their strategies also reflect implicit cultural meanings of home. Their material practices vary in degree of intended neutrality as they attempt to appeal to a generic imagined buyer or to a more specific one, and they employ strategies that help them influence buyers' perceptions of a house's past, present and future. Their practices illustrate how cultural intermediaries may attempt to leverage a multisensory environment to influence consumers outside of social interaction or verbal communication (Holbrook and Hirschman 1982).

\section{Channeling Imagination}

Staging Truism: Buyers will only purchase a house if they can imagine themselves living in it... and they need our help to do so! 
Stagers believe that buyers must be able imagine themselves in a home before they will choose to buy it. They also believe that buyers need help in order to envision their lives in a house. Stagers identify three primary reasons that buyers need their help in the envisioning process, and they orient their practices to address these issues: 1) Buyers are likely to be distracted by minor material problems, 2) they lack the imagination needed to mentally replace the current owner's furnishings (or lack thereof) with their own, and 3) the less a house reflects the buyer's aspirational lifestyle, the harder it will be for the buyer to imagine living there. This emphasis on envisioning and the various barriers to envisioning informs stagers' choices and is expressed in many of the codes I developed, which are grouped in the code category Channeling Imagination. ${ }^{4}$ One stager characterizes this work of channeling buyers' imaginations as the central goal and contribution of home staging: "Overall, staging goes beyond furniture placement and filling a house with inventory...staging is about creating style that inspires a buyer's excitement as they visualize themselves emotionally and physically "at home" in the house." (D200) Stagers have many strategies for directing buyers' imaginations, including Optimizing neutrality (193 quotations), Facilitating buyer imagination - Future (221 quotations), and Demographic staging (108 quotations). Figure 2. displays characteristic statements illustrating stagers' belief in envisioning's importance and in buyers' envisioning ineptitude.

\footnotetext{
${ }^{4}$ It is necessary to note that the three primary ways of conveying livability around which I have organized this analysis (targeting senses, channeling imagination, and maximizing perceived value) are not neatly discrete or mutually exclusive in practice. Any particular staging strategy may support multiple of these goals at the same time. For example, insisting on cleanliness (code: Emphasizing cleanliness) will affect what buyers smell and see in a house, may support envisioning by eliminating the distraction of messiness and dirt, and may increase a home's perceived value by making it appear in good repair. I have categorized the codes by what I have determined to be their primary orientation, as described by stagers, but I include practices from each category wherever they are relevant in the analysis.
} 
Figure 2.

\begin{tabular}{|c|c|}
\hline Importance of Envisioning & Buyers Need Help Envisioning \\
\hline $\begin{array}{l}\text { "The first step to getting buyers to make an } \\
\text { offer on your home is to impress them with its } \\
\text { appearance so they begin to envision } \\
\text { themselves living there." (D5) }\end{array}$ & $\begin{array}{l}\text { "Create other vignettes throughout the home- } \\
\text { such as a chess game in progress - to help buyers } \\
\text { envision living there." (D5) }\end{array}$ \\
\hline $\begin{array}{l}\text { "Buyers need to be able to visualize themselves } \\
\text { in the home." (Comment on D72) }\end{array}$ & $\begin{array}{l}\text { "Buyers only know what they see, not the way it is } \\
\text { going to be." (Barb Schwarz, D53) }\end{array}$ \\
\hline $\begin{array}{l}\text { "Every agent knows that the moment their } \\
\text { buyer is visualizing themselves in the home, the } \\
\text { offer comes next. Why? Because people buy on } \\
\text { emotion and being able to "see" your family } \\
\text { living in the space is essential!" (D146) }\end{array}$ & $\begin{array}{l}\text { "Because many buyers have difficulty envisioning a } \\
\text { room in any other way than the way they see it, it's } \\
\text { important to either show or tell them the potential } \\
\text { uses for the room." (D21) }\end{array}$ \\
\hline
\end{tabular}

Stagers emphasize that buyers are apt to be distracted by easy-to-fix problems like paint color, clutter, and scuffs on the wall. These things get in the way of buyers envisioning themselves into a house that could potentially meet their needs. Because of this belief about buyers, stagers attempt to remove any distractions or obstacles that might impede buyers' imaginative work (codes: Making it easy for buyers; Deceiving/Distracting buyers). During my participant observation of a home staging, the home seller argued for the value of staging in this way. He said, "When a house is empty, the buyers' eyes will just go straight to the scuffs on the wall or other negatives, but having the staging draws their eyes elsewhere" (Fieldwork, 6/19/17; codes: Deceiving/Distracting buyers; Optimizing home features). Staging can "de-emphasize [a] lack of good space planning" (D10), prevent buyers from overlooking positive features (D82), and avoid confusion caused by "too much furniture, undefined entrances and awkward walkways." (D88) Stagers de-clutter, depersonalize, and remove cross-purpose items to clarify ambiguous rooms (codes: Decluttering; Optimizing neutrality; Displaying function). They try to minimize any material features that buyers might perceive as problematic, unattractive, or incompatible with the lifestyle to which they aspire. 
Eliminate damaged and soiled items, get rid of half of the furniture and rearrange the other half, and remove any personal items. It is important to give the buyers the ability to see themselves in the property. (D9)

Remove anything that will distract buyers from seeing your property, including personal collections (yes, that sports memorabilia room has to go!), a wall of family photos, newspapers, books and magazines, etc. (D131)

As these excerpts illustrate, stagers try to anticipate which material objects are likely to distract buyers from the more permanent and important home features. These include objects that make a room feel small, like oversized or too much furniture (code: Emphasizing spaciousness), objects that convey dirtiness or disrepair (code: Emphasizing cleanliness), and items that are too closely linked to the identities of the owners (code: Optimizing neutrality).

Stagers also assert that buyers cannot envision themselves in a house that is vacant, because they will struggle to imagine how to use the space and what their possessions would look like in the rooms. Vacant houses are disparaged by stagers both for feeling 'cold' and for undermining buyers' ability to envision their lives in the space. As one author put it:

Don't keep an empty home empty. Buyers can struggle in picturing themselves moving in if a home is left empty. Vacant homes can feel cold and rooms can look smaller than they really are...If your listing is vacant, consider staging it to bring in furniture and accessories to help define the various rooms' functions. (D63)

Stagers seek to depersonalize houses, so that they are less specific to the current owners, and more accessible to potential buyers. However, stagers also believe that overly neutral or anonymous spaces feel barren and uninviting. Too many lifestyle-specific items, and buyers will be unable to mentally displace these objects and imagine their own belongings in the house; too few lifestyle-specific items, and buyers will struggle to imagine how the house could be functional and inviting. Stagers add strategic objects and lifestyle hints to enable buyers' envisioning process (code: Facilitating buyer imagination - Future). They paint walls in fashionable and mood-inducing colors (codes: Emphasizing color; Creating a mood; Following 
trends), suggest lifestyle activities via vignettes, and arrange furniture to optimize home features (codes: Optimizing home features; Displaying function). They pursue these material strategies in light of their goal of providing scaffolding for buyers' imaginations.

All of this emphasis on envisioning reveals that stagers are highly aware of the importance of an embodied sense of fit (Allen 2002) or belonging (Koklic and Vida 2009) in the consumption process. They are trying to facilitate an experience of fit for buyers even though they never meet the buyer and can only guess at who they are likely to be. While there is consensus among stagers that a balance of neutrality and specificity is essential, they do not agree on how to strike this balance. As Patricia Meyer, an experienced stager tells me,

As the stager, you want to create emotional connection, to make it warm and inviting. The main goal is to make them say, 'I want it. I want it all!' And I've had times when we ended up selling all the staging. That tells us we have really zeroed in on our buyer...You know you've really done your job if they walk in and say, "I love the house, I love the furniture, I love everything." (Author interview, 6/28/17)

Patricia describes staging success as creating a physical environment that maps onto a buyer's lifestyle so effectively that the buyer immediately feels at home in the house, and can imagine living in the space just as it is. As stagers attempt to arrange the material environment of houses to appeal to buyers' lifestyles, some of their practices are based on principles that they believe are universal, or that will make every house more attractive to every buyer. These include emphasizing cleanliness, spaciousness and newness (codes: Emphasizing cleanliness; Displaying spaciousness; Displaying newness). They start with the assumption that houses are more attractive if they are clean, that displaying more space is preferable, and that finishes and objects that indicate newness will communicate good value and style to buyers.

However, as suggested by Patricia's description above, many of their practices are targeted to a more specific imagined buyer. Many stagers go beyond trying to find a general 
balance of neutrality and attempt to target specific demographics ${ }^{5}$ (codes: Demographic staging;

Optimizing neutrality). Some stagers argue that staging should be as targeted to the anticipated

buyer as possible.

Before decisions are made on wall color, furniture, accessories, or artwork, [the stager] researches the neighborhood to get a sense of who is living there. He gets a feel for the age group, such as whether the locals are single, young married couples starting families or retirees. He does this by visiting the local hangouts-the coffee shops, bookstores, and pubs to name a few... Once the real estate agent is on board with his vision, [the stager] puts together his design plan and stages to the appeal of that particular segment of the buyer pool, instead of staying so generic. (D61)

A professional Stager will work closely with an experienced Realtor ${ }^{\circledR}$ to determine the demographic of the "most likely buyer" of a particular house. Then the Stager will get to work and make sure the house is prepared to target that audience... a four Bedroom Colonial in Buckingham Township may be likely to be purchased by a growing family or a couple and may get a different "look" than a condo in New Hope Boro or Solebury Township, where the likely next owner might be professionals or a new first time homeowner. (D55)

I observed this strategy in the show home of a regional homebuilder. In addition to being fully staged with furniture and décor, with two bedrooms clearly staged for young children, the home was staged with mock family photos in several rooms. The individuals in the photos reflected the builder's imagined buyer: A white, married couple in their 30's with two small children. (Fieldwork, 6/27/17) When I asked Karen, a stager and realtor whose open house I observed, how much she thinks about potential buyers when staging a house, she told me, "Well, you're really just trying to think about the house and have the staging be consistent with the house.

Here, this is a craftsman style house, so I knew I was going to be using furniture that had square legs and those types of lines to mimic that design style in the house." Karen emphasizes the characteristics of the house over the demographics of the potential buyer, but when she goes on

\footnotetext{
${ }^{5}$ I found one comment voicing concern over this trend: "I just had a cautionary thought. In order to be nondiscriminatory, we have been trained to advertise the house, NOT an expected/intended buyer. If you are targeting a certain type of buyer, you may run into someone who feels they don't have an equal shot at buying in that neighborhood." (Comment on D61, "Staging 'Outside the Box': Is the Face of Home Staging Changing?"; emphasis in original)
} 
to think about the house in its neighborhood context, it is clear that buyer demographics inform her staging choices. She says:

I think you have to know the neighborhood and the typical buyer that buys in this neighborhood, and just stay consistent with that. You know? This house is most likely to be purchased by a family. A family will probably buy this house. That's why I staged it upstairs to suggest that you could make that [room] into a kid's bedroom. (Fieldwork, $6 / 11 / 17)$

By considering the social demographic of her likely buyer, she is able to anticipate what kinds of features they will find desirable, and may organize the material environment of the house to emphasize those features. This work of anticipating the desires of the buyer is central to stagers' attempts to channel buyers' imaginations (codes: Analyzing buyer behavior; Facilitating buyer imagination - Future).

Demographic staging offers realtors some specific guideposts as they attempt to enable potential homebuyers to see themselves in a house that is for sale, but it also means that in attempting to cultivate the experience of livability for some buyers, they decrease the likelihood that buyers outside the imagined demographic will feel at home in the house. Homeowners who purchase homes in neighborhoods where they feel like cultural outsiders often feel they must justify their presence and belonging (Gram Hanssen and Bech Danielsen 2004), and potential buyers are less likely to purchase a house if it does not align with how they see themselves or how they want to be seen by others (Sirgy et al. 2005). While some stagers and realtors choose to forgo the additional research and time demographic staging requires, and others reject its utility by pointing to the heterogeneity of many neighborhoods, assumptions about potential buyers influence all stagers and are implicit even in their ideas about what is neutral. 


\section{Maximizing Perceived Value}

While stagers attempt to stoke buyers' emotions and imaginations, they recognize that buyers are also rational and practical in their home buying decisions. There is both theoretical (Iyer and Kuksov 2010) and substantive (Lane et al. 2015) evidence that buyers are capable of separating their attraction to a house from its market value. Among realtors and stagers, it is well recognized that a house will not sell if it is overpriced for the market, regardless of how beautifully it is staged (codes: Outweighing staging; Importance of price). As Lisa, the owner of a real estate company in Texas explained, "“What sells homes? Is it the marketing? Is it the realtor? Is it the photography? Is it this? Is it that?' No, it's the price." (Author interview, 12/14/15) And while some sources within the staging industry claim that staging can increase the market value of a home ${ }^{6}$, experimental research suggests that buyers are not willing to pay more for staged houses (Lane et al. 2015). At the same time, determining the value of a house is neither straightforward nor objective. As in many fields of production, price is influenced by a social process of interaction and meaning making (Espeland and Stevens 1998; Velthuis 2003), and is subject to the mood and fluctuation of the market (Munro and Smith 2008). There is evidence that buyers are wiling to pay more for a house they love and are afraid of losing (Christie et al. 2008; Munro and Smith 2008), and that realtors can influence buyers' perceptions of value by showing them homes in a particular sequence and by creating a sense of urgency (Besbris 2016).

\footnotetext{
${ }^{6}$ Within the documents I analyzed, these claims were often based upon research done by staging training organizations, and using the reported perceptions of real estate agents and stagers, and so do not offer a very robust degree of reliability. E.g. "A recent survey showed, in the opinion of 1,000 real estate professionals, that the projected ROI for staging to be as high as 589 percent." (from D69: Rae 2011, "Sex Sells!...Did I Catch Your Attention?")
} 
It is therefore the job of the home stager to make a house appear to be a value for the price. The overarching goal is to make it easy for buyers to say "yes" to the house (code: Making it easy for buyers). There are multiple aspects to this goal because there are many ways that stagers may attempt to convey value. Stagers strive to communicate value by convincing buyers they are getting a lot from the house for the price and they communicate value by minimizing perceived future costs (code: Displaying value). For the former, stagers may try to create as much usable space as possible or demonstrate how rooms can be used for multiple purposes, communicating to buyers that they are getting maximum utility out of the physical space of the house (codes: Emphasizing spaciousness; Displaying function). They may display as many new or up-to-date features as possible in order to convey stylishness and good repair (code:

Displaying newness). They may minimize anticipated costs by removing broken or outdated items. They may attempt to transform possible negatives, like unusual architecture, into positives through styling, lighting and displaying potential functions (codes: Optimizing home features; Displaying function).

Stagers attempt to control how buyers perceive their futures in a house, both in terms of lifestyle and in terms of the costs that living there will incur. Staging advice often sounds like this: "Pay attention to the condition of the walls: If the walls are beat up, dirty or chipped, it can distract a buyer and negatively impact the sale price. 'Paint is the cheapest, easiest, and fastest fix you can do on a house,' says Gould." (D29) Because houses are the largest and most significant durable good people purchase in personal consumption, home stagers - as cultural intermediaries - have the difficult job of constructing an environment that will not only be attractive to the buyer in the moment, but will convey the impression that this house will facilitate the buyers' desired life for years to come. This is another reason why stagers emphasize 
cleanliness - not only because clean houses are more attractive, but also because cleanliness can influence buyers' perceptions of future costs (codes: Emphasizing cleanliness; Facilitating buyer imagination - Future).

Dust, cobwebs, and bugs tend to take over if routine cleaning isn't maintained. Some buyers get the impression that a house will require repairs if it looks dirty, cluttered or abandoned - which can dramatically impact whether they make an offer and how much they offer. (D21)

Stagers encourage sellers to clean as extensively as possible, repair small signs of damage, and update outdated aesthetics so that buyers will not see future costs all around them (codes:

Displaying newness; Emphasizing cleanliness). In staging a space to appear well maintained, fashionably updated and clean, stagers attempt to contribute to the home's perceived livability by removing perceived costs and portraying the home as a high quality product (code: Displaying value).

Clarifying the function of rooms within the house is another staging strategy for increasing buyers' perceptions of value (code: Displaying function). A room that appears awkward or superfluous might cue buyers to begin thinking about the renovations they will have to do or the furniture they will have to buy before the room will be functional. As the below quote emphasizes, demonstrating the usability of rooms within a house can encourage buyers to see more value in it.

[Staging benefits vacant homes because] empty rooms look smaller to buyers, who more often than not will think their favorite sectional or king-sized bed is too big. In larger homes, buyers will question if they have enough furniture. Either way they'll be calculating the additional cost of new furniture rather than focusing on the home. (D123)

And finally, stagers attempt to boost buyers' evaluations of houses by making the features of the home look and function as well as possible (code: Optimizing home features). Their practices in this vein include highlighting unique or impressive architecture, staging rooms to display 
flexibility of function, and bringing in lamps and removing blinds to present spaces in a literal better light (code: Emphasizing light). They may paint walls lighter colors to make a room appear larger (code: Emphasizing spaciousness) or remove old carpeting to reveal more desirable wood floors underneath. Their specific material and aesthetic choices are based upon what they perceive to be widely acknowledged trends and style principles (code: Following trends). Zoe, a semi-retired realtor and stager describes how even sellers are aware of these principles: "I often arrive at the seller's house for the first time and they're already saying, 'I know I need to paint all my walls beige. I know I need to take this stuff off the refrigerator and take these things off the walls.' So they know a lot about what to do.” (Author interview, 6/7/17)

When buyers evaluate the value of a house, they are not only considering the quality of the object in relation to its price; they are also considering how well the house appears to meet their functional needs. Buyers consider a range of functional and practical factors, including the price, size, number of bedrooms and layout of potential homes (Anderson et al. 2017; Sirgy et al. 2005). It is essential to find a home that meets one's needs for everyday living, and homebuyers are more likely to purchase a house if its functional qualities align with their preferences (Sirgy et al. 2005). This "functional congruity" (Sirgy et al. 2005) is an important factor in determining what home a potential buyer will ultimately purchase. Even though homebuyers may hypothetically evaluate functional congruity objectively by comparing the home's features to their practical needs (i.e. "We need three bedrooms, and this house only has two"), perceptions of congruity are also subjective because the home buying decision is oriented toward imagining future possibilities. While a house may currently only have two bedrooms, instead of a family's preferred three, the family may imagine adding a third bedroom in the basement or converting the den into a bedroom, and if the home is staged to suggest these possibilities, they may be more 
likely to perceive the home as meeting their practical needs. All of these strategies for influencing buyers' perceptions of demonstrate how stagers' project of constructing livability targets buyers' rationality, as well as their imaginations and emotions. When stagers explain how they attempt to boost a home's perceived value, and why they believe certain practices are effective, they also reveal the temporal orientations of their practices. Buyers' perceptions of value are influenced both by anticipated future costs and by impressions of well the home has been cared for by its previous owners.

\section{Conclusion}

Buying a house is a complex, multi-dimensional decision, and there are many factors that can influence a buyer's choice. Along with practical factors like budget, number of rooms, and location, there is a range of less objective factors, many of which are outside the influence of stagers. These include buyers' perception of the neighborhood (Gram Hanssen and Bech Danielsen 2004), family and intimate others' opinions and influence (Levy and Lee 2004), interaction with their realtor and the order in which they view homes (Besbris 2016), and the current mood of the housing market (Christie et al. 2008; Munro and Smith 2008). However, previous research (Bourdieu 2005; Jørgensen 2015; Munro and Smith 2008) and my own fieldwork indicate that buyers' embodied experience within a house is central to their ultimate choice. This experience is the target of stagers' practices. Using a wide range of material strategies, home stagers attempt to facilitate an embodied experience of alignment between buyers' sense of self and ideas of home and the physical environment of a house. Home stagers attempt to facilitate this alignment with the hope that buyers will be inclined to purchase the staged house. 
It is clear that this alignment is multifaceted and experiential. It is also clear that buyers' perceptions of alignment or fit in a house are open to stagers' influence. I conceptualize this alignment as a perception of livability, or the degree to which buyers perceive that a house is desirable, will facilitate their imagined future life, and represents a good value. Desire, envisioning and evaluation are all interactive processes that stagers shape by conveying cultural meanings through the material environment of the house. In analyzing stagers' strategies, I have demonstrated that they aim to influence buyers in three distinct ways: through sensory cues, by directing their imaginations, and by displaying value. In light of research indicating the importance of emotion and embodied experience in home buying (e.g. Besbris 2016; Bourdieu 2005; Jørgensen 2015; Munro and Smith 2008), their strategies reveal how this embodied experience is influenced by cultural intermediaries. Apart from the influence of social interaction on the home buying decision (Besbris 2016; Levy and Lee 2004), and on consumption decisions in general (Prus 1989; Bandelj 2009; Bettman et al. 1998), the material environment of the home is a central actor in the purchase decision, and this environment is strategically arranged by home stagers. The importance of the arrangement of the material environment in consumption settings - and cultural intermediaries' role in this arranging - has been noted by cultural sociologists (Bartram 2017; Grazian 2012; Griswold et al. 2013), but this analysis is the first to consider cultural mediation and materiality in home buying, and as such, reveals a dynamic cultural process that influences this socially and economically significant purchase.

Additionally, home stagers and their work as cultural intermediaries lie outside the worlds of art and entertainment, which have received considerable attention as cultural industries. Home stagers are distinct in that they are not shaping a consumer experience so as to encourage loyalty to one brand or company. Ninety percent of buyers purchase houses on the 
resale market, while only $10 \%$ of buyers purchase newly constructed houses (Anderson et al. 2017), This means that most houses are not associated with any brand or company. Home stagers are not trying to encourage visitors to come back for future visits (as cultural intermediaries in arts, entertainment and tourism often do), nor are they trying to encourage brand loyalty or get as many people to make a purchase as possible (as cultural intermediaries in most shopping contexts do); rather, they are attempting to construct an experience for potential buyers that makes them want to purchase one specific home. And, while having multiple buyers who want to buy a single home can lead to a higher selling price for the seller, ultimately, stagers only need to convince one qualified buyer to choose the house.

In addition to illuminating an understudied realm of cultural mediation, this analysis of home stagers reveals additional axes of variation along which strategies of cultural mediation may vary. As stagers appeal to buyers' senses, imaginations, and evaluative processes, their specific practices vary in their temporal orientation and their degree of neutrality. I expected that stagers would attempt to encourage buyers to imagine their futures in potential houses, but I was surprised that stagers also tried to manage buyers' perceptions of the home's past. Sights and smells had the power to tell a sensory story about the home that began with previous and current owners, and stretched into a potential future with the prospective buyers. This discovery uncovered significant meanings of home that are specifically tied to the past, including the importance of individual autonomy in homeownership in the United States (Hockey 2002), and the way that perceptions of previous owners' activities within a house can affect buyers' perceptions of the house's current value. These meanings could not be parsed without considering the temporal orientation of stagers' strategies. I suggest that this is likely to be true 
across fields of cultural mediation: attending to the temporal orientation of intermediaries' actions will reveal previously invisible meanings of the relevant cultural object.

Similarly, attending to the degree of neutrality in home stagers' practices uncovers previously overlooked processes shaping the home buying decision. A family's economic resources determine whether or not a certain home is affordable, but whether or not they feel that they belong in a particular house-or a particular neighborhood-depends on a sense of personal fit that is rooted in their cultural capital (Gram Hanssen and Bech Danielsen 2004). A house will appear more or less livable to a particular family or individual based on the lifestyle that is implied by the material characteristics of the house. Stagers attempt to construct livability for potential buyers, and their attempts are based on ideas about who the buyer is likely to be. Assumptions about lifestyle preferences and family characteristics are both explicit and implicit in their choices and strategies. When stagers draw upon implicit cultural meanings of home to guide their practices, and when they attempt to anticipate which features buyers will appreciate, they necessarily choose to give off some lifestyle cues while suppressing others. This act of curation is a mechanism of exclusion, even if stagers are unaware of the implicit biases guiding their choices. I expect this axis of variation to be relevant across fields of cultural mediation, as intermediaries seek to target a generic consumer or a very specific consumer. Attending to the degree of neutrality in cultural intermediaries' actions should provide insight into processes of exclusion and inclusion in their fields. 


\section{References:}

Allen, Douglas E. 2002. "Toward a Theory of Consumer Choice as Sociohistorically Shaped Practical Experience: the Fits-Like-a-Glove (FLAG) Framework.” Journal of Consumer Research 28(4):515-32.

Anderson, Jamie et al. 2017. Consumer Housing Trends Report 2016. Zillow Group, Inc.

Avitts, E. 2014. "Home Staging in Twenty-First Century America: Doesn't It Look Like a Happy Place to Live?." American Studies in Scandinavia.

Babon, Kim M. 2006. "Composition, Coherence, and Attachment: the Critical Role of Context in Reception.” Poetics 34(3):151-79.

Bandelj, Nina. 2009. "Emotions in Economic Action and Interaction.” Theory and Society 38(4):347-66.

Bartram, Robin. 2017. "Housing Historic Role Models and the American Dream: Domestic Rhetoric and Institutional Decision-Making at the Tenement Museum." Qualitative Sociology 40:1-22.

Besbris, Max. 2016. "Romancing the Home: Emotions and the Interactional Creation of Demand in the Housing Market." Socio-Economic Review mww004.

Bettman, James R., Mary F. Luce, and John W. Payne. 1998. "Constructive Consumer Choice Processes.” Journal of Consumer Research 25(3):187-217.

Bielby, William T. and Denise D. Bielby. 1994. “'All Hits Are Flukes': Institutionalized Decision Making and the Rhetoric of Network Prime-Time Program Development." American Journal of Sociology 1287-1313.

Bourdieu, Pierre. 1984. Distinction: a Social Critique of the Judgement of Taste. Harvard University Press.

Bourdieu, Pierre. 2005. The Social Structures of the Economy. Cambridge, UK: Polity Press.

Bright, Susan and Nicholas Hopkins. 2011. "Home, Meaning and Identity: Learning From the English Model of Shared Ownership." Housing, Theory and Society 28(4):377-97.

Chapman, Tony and Jenny Hockey, eds. 2002. Ideal Homes? London: Routledge.

Chapman, Tony. 2002. "Stage Sets for Ideal Lives: Images of Home in Contemporary Show Homes." in Ideal Homes? Tony Chapman and Jenny Hockey. (Eds.) London: Routledge.

Christie, Hazel, Susan J. Smith, and Moira Munro. 2008. "The Emotional Economy of Housing." Environment and Planning A 40(10):2296-2312.

Cohen, Erik. 1988. "Authenticity and Commoditization in Tourism." Annals of tourism research 15(3):371-86. 
Cronin, Anne M. 2004. "Regimes of Mediation: Advertising Practitioners as Cultural Intermediaries?.” Consumption Markets \& Culture 7(4):349-69.

Csikszenthmihalyi, M and E Rochberg-Halton. 1981. The Meaning of Things. London: Cambridge UP.

Dickinson, Greg, Casey Malone Maugh, and Andrea Kaston Tange. 2004. Defining Visual Rhetorics. edited by C. A. Hill and M. Helmers. London: Lawrence Erlbaum Associates.

Douglas, Mary. 1991. “The Idea of a Home: a Kind of Space.” Social Research 287-307.

Douglas, Mary. 2003. Purity and Danger. Routledge.

Dunn, Meredith. 2017. 2017 Profile of Home Staging. Washington, DC: National Association of REALTORS.

Ellis, G D. and J R. Rossman. 2008. "Creating Value for Participants Through Experience Staging: Parks, Recreation, and Tourism in the Experience Industry." Journal of Park \& Recreation Administration.

Espeland, Wendy N. and Mitchell L. Stevens. 1998. "Commensuration as a Social Process." Annual Review of Sociology 24(1):313-43.

Garber, Marjorie B. 2000. Sex and Real Estate: Why We Love Houses. Schoken Books.

Gillis, John R. 1997. A World of Their Own Making: Myth, Ritual, and Quest for Family Values. Harvard University Press.

Glaser, Barney G. and A Strauss. 1967. "The Discovery of Grounded Theory.” Pp. 1-115 in The Discovery of Grounded Theory: Strategies for Qualitative Research. Chicago: Aldine Publishing Company.

Golab, C R. 2013. “Using Design to Make the Home Whole': Meaning and the Model HomeArizona in the 1950s."

Graham, Lindsay T., Samuel D. Gosling, and Christopher K. Travis. 2015. "The Psychology of Home Environments.” Perspectives on Psychological Science 10(3):346-56.

Gram Hanssen, Kirsten and Claus Bech Danielsen. 2004. "House, Home and Identity From a Consumption Perspective." Housing, Theory and Society 21(1):17-26.

Grazian, David. 2012. "Where the Wild Things Aren't.” The Sociological Quarterly 53(4):54665 .

Griswold, Wendy. 1987. "The Fabrication of Meaning: Literary Interpretation in the United States, Great Britain, and the West Indies.” American Journal of Sociology 1077-1117.

Griswold, Wendy. 1981. "American Character and the American Novel: an Expansion of 
Reflection Theory in the Sociology of Literature." American Journal of Sociology 740-65.

Griswold, Wendy, Gemma Mangione, and Terence E. McDonnell. 2013. "Objects, Words, and Bodies in Space: Bringing Materiality Into Cultural Analysis." Qualitative Sociology 36(4):343-64.

Halton, Eugene. 2008. "The Art and Craft of Home.” Pp. 1-33 in The Great Brain Suck. Chicago.

Hayes, Deborah and Nicola MacLeod. 2016. "Packaging Places: Designing Heritage Trails Using an Experience Economy Perspective to Maximize Visitor Engagement." Journal of Vacation Marketing 13(1):45-58.

Hockey, Jenny. 2002. "Houses of Doom.” In Ideal Homes? Tony Chapman and Jenny Hockey, (eds). London: Routledge.

Holbrook, Morris B. and Elizabeth C. Hirschman. 1982. "The Experiential Aspects of Consumption: Consumer Fantasies, Feelings, and Fun." Journal of Consumer Research 9(2):132.

Hurdley, R. 2006. "Dismantling Mantelpieces: Narrating Identities and Materializing Culture in the Home." Sociology.

Iyer, G and D Kuksov. 2010. "Consumer Feelings and Equilibrium Product Quality.” Journal of Economics Management Strategy.

Jansen, Robert S. 2008. "Jurassic Technology? Sustaining Presumptions of Intersubjectivity in a Disruptive Environment." Theory and Society 37(2):127-159.

Johnson, Kimberly R. and Bjarne M. Holmes. 2009. "Contradictory Messages: a Content Analysis of Hollywood-Produced Romantic Comedy Feature Films." Communication Quarterly 57(3):352-73.

Jørgensen, Cecilie J. 2015. "The Space of the Family: Emotions, Economy and Materiality in Homeownership." Housing, Theory and Society 1-16.

Kaika, Maria. 2004. "Interrogating the Geographies of the Familiar: Domesticating Nature and Constructing the Autonomy of the Modern Home." International Journal of Urban and Regional Research 28(2):265-86.

Knutson, Bonnie J. and Jeffrey A. Beck. 2004. "Identifying the Dimensions of the Experience Construct." Journal of Quality Assurance in Hospitality \& Tourism 4(3-4):23-35.

Koklic, M K. and I Vida. 2009. "A Strategic Household Purchase: Consumer House Buying Behavior." Managing Global Transitions.

Konieczny, Mary E. 2009. "Sacred Places, Domestic Spaces: Material Culture, Church, and Home at Our Lady of the Assumption and St. Brigitta." Journal for the Scientific Study of 
Religion 48(3):419-42.

Lane, M A., M J. Seiler, and V L. Seiler. 2015. “The Impact of Staging Conditions on Residential Real Estate Demand." Journal of Housing Research.

Levy, D S. and C K.-C. Lee. 2004. "The Influence of Family Members on Housing Purchase Decisions." Journal of Property Investment Finance 4(5):320-38.

Low, Setha M. 2001. "The Edge and the Center: Gated Communities and the Discourse of Urban Fear." American anthropologist.

Low, Setha M. 2008. "Fortification of Residential Neighbourhoods and the New Emotions of Home." Housing, Theory and Society 25(1):47-65.

Mallett, Shelley. 2004. "Understanding Home: a Critical Review of the Literature." The Sociological Review 62-89.

Marx, Jonathan I., Jennifer C. Solomon, and Lee Q. Miller. 2004. "Gift Wrapping Ourselves: the Final Gift Exchange.” The Journals of Gerontology Series B: Psychological Sciences and Social Sciences 59(5):S274-80.

McDonnell, Terence E. 2010. "Cultural Objects as Objects: Materiality, Urban Space, and the Interpretation of AIDS Campaigns in Accra, Ghana1." American Journal of Sociology 115(6):1800-1852.

Mitchell, Terence R. and Lee R. Beach. 1990. ““... Do I Love Thee? Let Me Count ...’ Toward an Understanding of Intuitive and Automatic Decision Making." Organizational Behavior and Human Decision Processes 47(1):1-20.

Munro, Moira and Susan J. Smith. 2008. "Calculated Affection? Charting the Complex Economy of Home Purchase.” Housing Studies 23(2):349-67.

Negus, Keith. 2002. "The Work of Cultural Intermediaries and the Enduring Distance Between Production and Consumption." Cultural Studies 16(4):501-15.

Pine, B.J. and Gilmore, J.H., 1999. The experience economy: work is theatre \& every business a stage. Harvard Business Press.

Prus, C. R. 1989. Making Sales: Influence as Interpersonal Accomplishment, London, Sage.

Rogers, Dallas. 2013. "The Poetics of Cartography and Habitation: Home as a Repository of Memories.” Housing, Theory and Society 30(3):262-80.

Schudson, M. 1989. "How Culture Works: Perspectives From Media Studies on the Efficacy of Symbols." Theory and Society 18(2):153-80.

Schwarz, Barb. n.d. “ASP Home Staging Statistics.” Retrieved Jan. 11, 2018 (https://stagedhomes.com/mediacenter/stagingstatistics.php). 
Sirgy, M J., Stephan Grzeskowiak, and Chenting Su. 2005. "Explaining Housing Preference and Choice: the Role of Self-Congruity and Functional Congruity." Journal of Housing and the Built Environment 20(4):329-47.

Strauss, A and Juliet Corbin. 1990. "Techniques for Enhancing Theoretical Sensitivity and Axial Coding." Pp. 75-115 in Basics of Qualitative Research. Sage Publications, Inc.

Strauss, A and Juliet Corbin. 2007. "The Uses of Literature and Open Coding." Pp. 48-74 in Basics of Qualitative Research: Grounded Theory Procedures and Techniques. Thousand Oaks, CA: Sage Publications.

Swinyard, William R. 1993. "The Effects of Mood, Involvement, and Quality of Store Experience on Shopping Intentions.” Journal of Consumer Research 20(2):271.

Timmermans, S and I Tavory. 2012. "Theory Construction in Qualitative Research: From Grounded Theory to Abductive Analysis.” Sociological Theory 30(3):167-86.

Tsai, Shu-pei. 2005. "Integrated Marketing as Management of Holistic Consumer Experience." Business Horizons 48(5):431-41.

Turner, F. 2012. "The Family of Man and the Politics of Attention in Cold War America." Public Culture 24(1 66):55-84.

Umberger, Mary. 2011. "When Staging a Home for Sale, What's Important?.” Los Angeles Times, September 11, 1-3.

Velthuis, Olav. 2003. "Symbolic Meanings of Prices: Constructing the Value of Contemporary Art in Amsterdam and New York Galleries.” Theory and Society 32(2):181-215.

Warde, Alan. 2014. “After Taste: Culture, Consumption and Theories of Practice.” Journal of Consumer Culture 14(3):279-303. 